\title{
Use of benzidine for histological demonstration of haemoglobin in human bite marks
}

\author{
R T Allison, D K Whittaker
}

\begin{abstract}
Macroscopic evidence of bruising from human bite marks may be inconclusive and routine histochemical methods of showing extravasated erythrocytes can be unreliable. Leuco patent blue staining, for the presence of peroxidase, Amido black $B$, a tinctorial staining method for haemoglobin, Perls's reaction for ferric iron (haemosiderin), Masson-Fontana for melanin, Masson's trichrome, a connective tissue stain, and the benzidine reaction for haemoglobin peroxidase were carried out in three forensic cases and one experimental case. A modified benzidine method was the most reliable indicator of haemoglobin activity, especially where dispersion into extra-cellular tissues had occurred. The resilience of the erythrocyte peroxidase enzyme to temperature changes and fixation supports the concept of a "pseudo-peroxidase" in those cells.

It is concluded that free haemoglobin from bite marks, or indeed other forms of blunt trauma, may best be shown by the benzidine reaction and that exemption certificates for use of this prohibited substance may be worth pursuing.
\end{abstract}

Bite marks in human tissue may produce laceration of the epidermis, but in the absence of penetration of the skin, are visible because of bruising caused by the biting edge of the teeth, ${ }^{1}$ or by suction or pressure on the soft tissues. A bruise is the escape of blood into the tissues of a living person following rupture of vessels, usually capillaries, by the application of a blunt force. ${ }^{3}$ The elliptical shape of a human bite mark and the marks caused by individual teeth usually make recognition straightforward, but there are cases when it may be necessary for medicolegal reasons to prove that discolouration of the tissues at the site of pressure of a tooth, or teeth, is due to extravasation of blood and not some other cause such as pigmentation.

Extravasated erythrocytes will usually be demonstrable using standard histochemical tests, but extravasation of blood cannot always be diagnosed by the identification of intact erythrocytes, and Perls's reaction for haemosiderin may be negative. In a recent case a suspicion of bruising from a bite could not be confirmed histochemically and as a last resort the benzidine technique was applied to tissue sections, producing vividly positive results.

\section{Case histories}

CASE 1

This woman had been raped and murdered. The probable time of first examination of the body by a pathologist was within 12 hours of death. Rigor mortis was present and a post mortem examination was performed the same day. Although there was no detailed written record in the mortuary of the conditions under which the body was stored, it was reported that the body was frozen to $-16^{\circ} \mathrm{C}$ and thawed at least twice before the tissue described below was excised. Seventeen days after death one of us (DKW) examined the body for the presence of bite marks-an injury that could have been consistent with previous attacks by an emerging suspect. Bruises and mild abrasions were detected around the nipple of the left breast. Silicone impressions were made of the breast before and after thawing of the body for reasons to be described elsewhere. One week later and following thawing once more, the entire breast was amputated for microscopic examination. It was immersed in $10 \%$ neutral formalinsaline.

CASE 2

An 82 year old woman had been attacked and murdered at home. Examination of the body showed a large bruise on the outer thigh. A large area of this tissue, together with adjacent muscle, was removed and fixed in $10 \%$ neutral formalin-saline. It was subsequently established that she had been taking prophylactic anticoagulants.

\section{CASE 3}

This young woman sustained a vicious, fatal sexual attack, and the body featured many bite marks. One of these was excised from the elbow, fixed in $10 \%$ neutral formalin-saline, and paraffin wax sections prepared.

\section{EXPERIMENTAL STUDY}

An area of bruising was excised from the thigh of a female cadaver, frozen, and stored at $-16^{\circ} \mathrm{C}$, thawed to room temperature for two hours, refrozen under the same conditions, and finally thawed again and fixed in $10 \%$ neutral formalin-saline. This was an attempt to reconstruct the freezing history of the tissues excised in case 1 in so far as they were known. 


\section{Methods}

Blocks of tissue from each case were removed from the areas of putative bruising and chosen to include normal healthy tissue at one end. Pieces of tissue distant from the macroscopically bruised areas were selected for control purposes. Fixed tissue was processed to paraffin wax overnight using the Hypercentre (Shandon Scientific Ltd, Runcorn, Cheshire). The only unusual feature of the processing cycle was the inclusion of phenol-formalin in the first two stages, as recommended by Slidders and Hopwood. ${ }^{4}$ Sections $(4 \mu \mathrm{m})$ were cut and stained by the following standard methods ${ }^{5}$ : Leuco patent blue; Amido black B; Perls's reaction; Masson-Fontana; Masson's trichrome.

The benzidine method of Pickworth, as given by Pearse, ${ }^{6}$ was modified by using the reagent in a Coplin jar, taking all necessary precautions to protect the operator and the environment from the carcinogen.

\section{Results}

Areas corresponding to macroscopic bruising were often denuded of epithelium (fig 1). Furthermore, the dermis beneath these areas, whether or not it was covered by epithelium, showed condensation of some collagen fibres, visualised as an increased eosinophilia, and oedematous spaces between other fibre groups. These features were not present in the
Figure 1 Areolar region from breast of case 1 showing areas of loss of epithelial covering and condensation of connective tissue compatible with bite marks. There is no evidence of intact red blood cells or haemosiderin. (Haematoxylin and eosin.)

Figure 2 Section adjacent to that illustrated in fig 1 , stained by the modified Pickworth's benzidine technique and showing a positive particulate reaction.
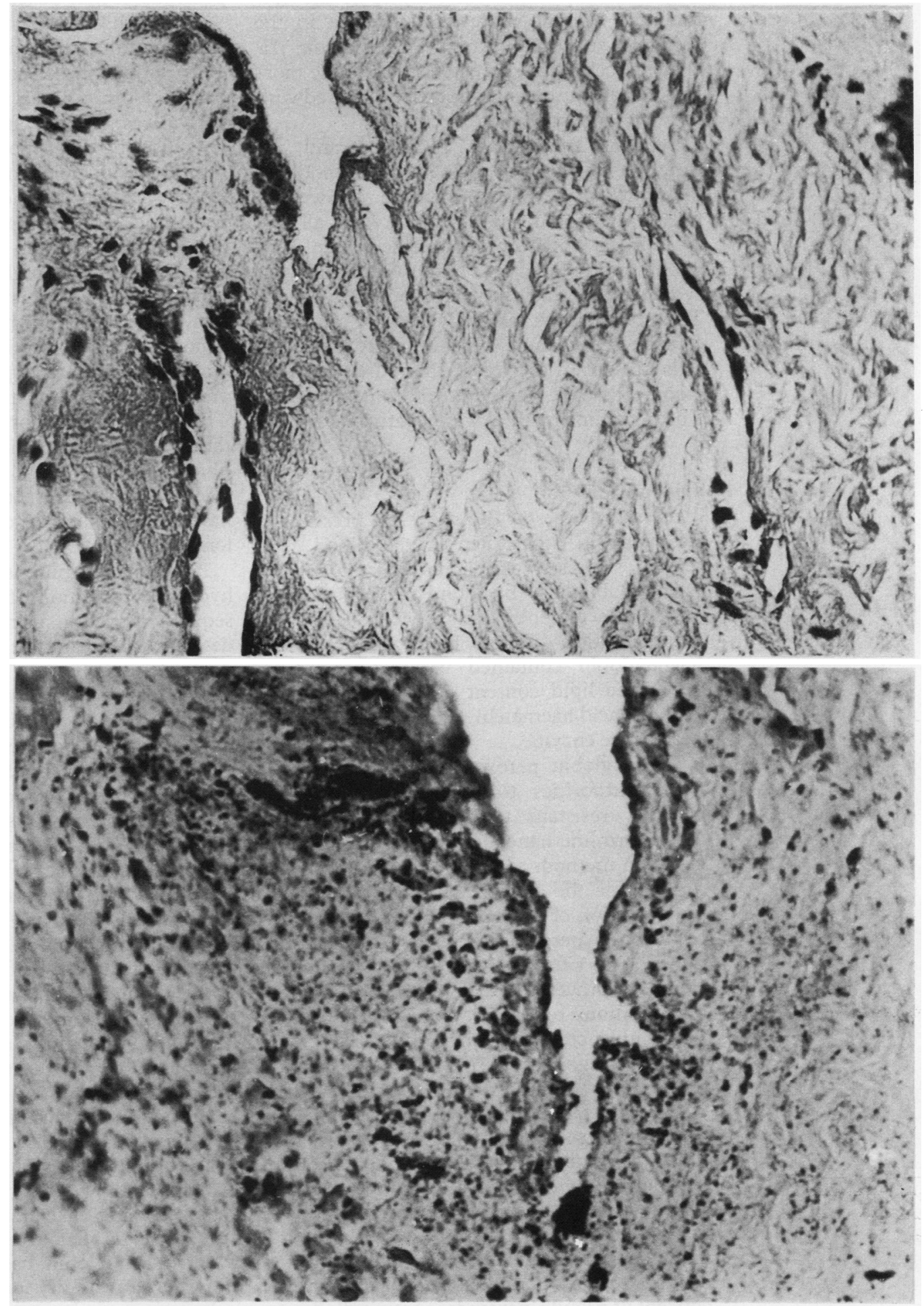
control tissues. Tissue that had been frozen and thawed and had therefore received delayed fixation showed quite reasonable microscopic morphological detail-in most cases nuclei were still intact and well stained. No intact red blood cells were seen, however, either within vessels or the surrounding connective tissues from both cases 1 and 3 and from the experimental study, although they were present in abundance in case 2.

The Lison-Dunn Leuco patent blue V method, Amido black 10B, and Perls's reaction produced a completely negative reaction in the suspect areas: control sections were positive. Masson-Fontana staining showed the presence of argentaffin pigment, presumably melanin, in the basal layers of the epithelium, with no increase in fall-out in the areas of suspected bites. The Masson trichrome technique served to enhance the morphological features in the sections stained with haematoxylin and eosin.

Sections from cases 1 and 3 and the experimental tissues stained by a modified Pickworth's benzidine method showed a finely pigmented blue positivity in all the areas from which epithelium had been denuded microscopically and which showed evidence of bruising macroscopically (fig 2). This staining was seen only in those areas and confirmed that there were no intact red blood cells present in the freeze thawed tissue. Red blood cells were stained in the control tissues. The benzidine method was negative in case 2 .

\section{Discussion}

It is rarely necessary to show the presence of haemoglobin other than in red blood cells. Lillie suggests that on occasion free haemoglobin may be found in the kidney in various haemoglobinurias. ${ }^{7}$ Methods for the demonstration of red blood cells, or the haemoglobin contained within, depend on either the lipid content of the cell envelope (Baker's acid haematein) or the presence of the peroxidase enzyme.

Haemoglobin peroxidase is considered by many authorities to be a relatively stable enzyme, resistant to both heating and to chloroform/methanol extraction. ${ }^{8}$ The basis of common methods to show peroxidase activity depends on the enzyme's capacity to catalyse the oxidation of aromatic amines and phenols by hydrogen peroxide, giving rise to dye formation at the site of reaction by a variety of chemical processes, such as polymerisation, precipitation, reduction. Benzidine, $\alpha$ naphthol, and leuco dyes are examples.

Lillie categorises three types of peroxidase ${ }^{7}$ : the highly labile tissue peroxidases, the relatively stable myeloperoxidases of the granulocyte series, and the heat and fixative stable peroxidase of haemoglobin. The term "pseudo-peroxidase" has been assigned by some workers to this latter variant, probably by Barka and Anderson," who state that, "the methods recommended for the demonstration of haemoglobin peroxidase are based on this concept of pseudo-peroxidase activity". Pearse considers that methods for haemoglobin peroxidase were intended primarily to show the presence of red blood cells by virtue of their haemoglobin content and that none of the available methods was of sufficiently high specificity to confirm haemoglobin outside red blood cells. ${ }^{6} \mathrm{He}$ did identify "thermostable tissue peroxidases" which appeared during autolysis and gave a positive result with benzidine. Lison stated that his leuco blue method did not stain such material. ${ }^{10}$ Pearse did not consider these tissue peroxidases to be of any importance and that the "pseudo-peroxidase" reactions could be taken as indicative of haemoglobin or haemochromogen pigment. Stevens also makes a bald statement that tissue peroxidases may be shown. ${ }^{11}$

Although Gomori considered his zinc patent methods to be superior for the demonstration of haemoglobin, he conceded that only intact haemoglobin, and not any protein-free derivatives, stained with the method. ${ }^{12}$

It has been proposed that the coloured reaction product of benzidine oxidation is a two stage event, ${ }^{9}$ with the initial production of benzidine blue, an intense though unstable compound, followed by full polymerisation and the production of the stable but less intense benzidine brown. This is an attractive proposition, but a search of the textbooks shows that almost without exception authors cite a blue, black, or grey reaction product as the end point of peroxidase demonstration using benzidine. This is also the authors' experience, and even though the intermediate product benzidine blue is reputed to be stable for a "period of weeks" only (sic), sections in our possession have remained that colour for very much longer.

Leuco patent blue is produced via nascent hydrogen reduction of patent blue and subsequent oxidation using endogenous peroxidase as the catalytic source of hydrogen peroxide reduction.

Tinctorial methods are believed by Bancroft and Stevens to show the presence of haemoglobin as opposed to associated peroxidase. ${ }^{11}$ These methods include the Dunn Thompson modification of van Gieson's ${ }^{13}$ method, Lendrum's highly selective Kiton red technique, ${ }^{14}$ and the Amido black 10B method of Putchler and Sweat. ${ }^{15}$ Van Gieson's methods are well known to be rate controlled structure affinity methods. The Amido black method is claimed to be highly selective for haemoglobin (and elastin) because of the $\alpha$ helical structure of the globin molecule and because most other tissue sites become blocked by tissue/tannic acid/phosphmolybdic acid complexes. The originators of the technique also place great importance on the use of Zenker's fixative to enhance selectivity, although this is disputed by others. ${ }^{16}$

Lendrum, an expert in tinctorial methods, considers that the highest selectivity is achieved using the benzidine methods and that only intact erythrocytes and not those from which haemoglobin has leached after death, show a useful affinity for dyes. ${ }^{14}$

In our cases microscopic changes of conden- 
sation of collagen fibres and the presence of oedema confirm the findings of Millington. The failure of benzidine to stain red blood cells in case 2 is puzzling. The body was examined within a few hours of death, the bruise, which was extremely bloody, was excised and immersion-fixed in formalin-saline immediately, and the victim had been taking warfarin. Without further detailed experimentation it would be speculative to suggest whether any or all of these factors accounted for the negative staining results. In the other cases and the experimental material the loss of haemoglobin and other constituents from the erythrocytes after death may have been enhanced by the freeze thaw process to which the tissue was subjected. Our results confirm the opinions of Lendrum $^{14}$ and Pearse $^{6}$ that tinctorial methods are of little use in the demonstration of haemoglobin and its associated metabolites when free in tissue. The apparent resilience of a peroxidase enzyme to heating and fixation suggests that the particular one associated with the erythrocyte deserves to be considered separately from other tissue peroxidases. Although not altogether an appropriate term, our findings tend to support the concept of a "pseudo-peroxidase" in erythrocytes. Our findings also confirm that benzidine methods are the most sensitive indicators of haemoglobin peroxidase activity, especially where these substances are dispersed in extracellular tissues.

Unfortunately, from a histochemical viewpoint, benzidine is a known carcinogen and a prohibited substance in the United Kingdom and many other countries. Negotiations are currently under way with the Health and Safety Executive in the United Kingdom for an exemption certificate so that the substance may be imported by the authors and used for this specific purpose. Currently, a licence is required for the importation and use of benzidine if the concentration is greater than $0.1 \%$ (Chapman I, November 1989, personal communication).

1 Millington PF. Histological studies of skin carrying bite marks. J Forensic Sci Soc 1973;14:239-40.

2 Kydd WL. Quantitative analysis of forces on the tongue. $J$ Dent Res 1956;35:171-4.

3 Polson CJ, Gee DJ, Knight B. Injuries: General Features. In: The essentials of forensic medicine. 4th ed. Oxford: Pergamon Press, 1985:97.

4 Slidders $W$, Hopwood D. Buffered phenol formaldehyde (pH 7.0 and pH 5.5): improved fixation in an enclosed tissue processor. Med Lab Sci 1989;46:74-6.

5 Culling CFA, Allison RT, Barr WT. Cellular pathology technique. 4th ed. London: Butterworths, 1985.

6 Pearse AGE. Histochemistry. Theoretical and applied. Volume 2. 4th ed. London: Churchill Livingstone, 1985.

Volume 2. 4th ed. London: Churchill Livingstone, 1985.
Lillie RD. Histopathologic technique and practical histoLillie RD. Histopathologic technique and practical
chemistry. 3rd ed. New York: McGraw-Hill, 1965.

8 Burstone MS. Enzyme histochemistry. New York: Academic Press, 1962.

9 Barka T, Anderson PJ. Histochemistry. New York: Harper and Row, 1963.

10 Lison L. Histochemie et cytochimie animales. 2nd ed. Paris: Gauthier-Villars, 1953.

11 Stevens A. Theory and practice of histological techniques. 2nd ed. London: Churchill Livingstone, 1982.

12 Gomori G. Microscopic histochemistry. Chicago: University of Chicago Press, 1952.

13 Dunn RE, Thompson EC. New haemoglobin stain for histologic use; slightly modified van Gieson stain. Pathol histologic use; s

14 Lendrum AC. The staining of erythrocytes in tissue sections. J Pathol Bacteriol 1949;61:443-8.

15 Putchler M, Sweat F. Amidoblack as a stain for haemoglobin. Archives of Pathology 1962;73:245-9.

16 Bancroft JD, Cook HC. Manual of histological techniques. London: Churchill Livingstone, 1984. 